\title{
DIÁLOGO ENTRE TRADIÇÃO DIRETA E INDIRETA: VARIANTES DA TRADUÇÃO LATINA DA OBRA DE ISAAC DE NÍNIVE NO TRACTATUS PAUPERIS DE JOHN PECHAM
}

\author{
CÉsar Nardelli Cambraia \\ Universidade Federal de Minas Gerais
}

\begin{abstract}
Resumo. A reconstrução do trajeto seguido pela obra de Isaac de Nínive na sua difusão em língua latina apresenta diversos desafios, dada a sua grande amplitude geográfica e temporal. No presente trabalho, examinam-se as citações de Isaac de Nínive no Tractatus Pauperis de John Pecham, a fim de obter melhores evidências sobre a história de sua difusão em língua latina e de refletir sobre relação entre tradição direta e indireta no processo de elaboração de edições críticas.
\end{abstract}

Palavras-chave. Isaac de Nínive, Língua Latina, crítica textual, edição crítica.

\section{ISAAC DE NÍNIVE: AUTOR, OBRA E TRADUÇÕES ${ }^{1}$}

IsAaC NASCEU EM Bet QATRAye (NO ATUAL QATAR) E FOI ORDENADO Bispo de Nínive no monastério de Bet 'Abe (no norte de atual Iraque) por Jorge, o Católico, em 676 d.C. Cinco meses depois, renunciou ao cargo e foi viver como anacoreta na montanha de Matut, na região de Bet Huzaye (na atual província do Cuzistão no Irã). Posteriormente, transferiu-se para o monastério de Rabban Shabur (também no atual Irã, talvez próximo a Shushtar), onde aprofundou seus conhecimentos das Sagradas Escrituras. Morreu cego e com idade avançada aprox. em 700 d.C. e foi sepultado no próprio monastério de Rabban Shabur (Brock, 1999-2000).

Chialà (2002: 66-83) considera, com base em pesquisas mais recentes, que estariam entre as obras genuínas três conjuntos de capítulos e dois fragmentos de uma outra coleção. A Primeira Parte é composta de 82 capí-

\footnotetext{
*Artigo recebido em 14.jan.2014 e aceito para publicação em 7.jul.2014.

${ }^{1}$ Uma versão preliminar deste trabalho foi apresentada oralmente na mesa redonda de crítica textual realizada durante a XI Semana de Letras, na Universidade de Ouro Preto, entre 25 e 28 de outubro de 2010.
} 
tulos; a Segunda Parte compõe-se de 41 capítulos (dos quais o $16^{\circ}$ e o $17^{\circ}$ correspondem respectivamente ao $54^{\circ}$ e ao $55^{\circ}$ da Primeira Parte); a Terceira Parte apresenta 17 capítulos (dos quais o $14^{\circ}$ e o $15^{\circ}$ correspondem respectivamente ao $22^{\circ}$ e ao $40^{\circ}$ da Primeira, e o $17^{\circ}$ corresponde ao $25^{\circ}$ da Segunda); a Quinta Parte compreende apenas dois fragmentos próprios. Vê-se que, conjuntamente, a obra de Isaac compreende pelo menos 137 capítulos distintos.

Dessas coleções importa aqui especificamente a Primera Parte: do original em siríaco, foi traduzida para o grego em fins do séc. VIII ou princípios do séc. IX por dois monges - Patrikios e Abramios - do mosteiro de Mar Sabbas, situado próximo a Jerusalém, e do grego para o latim por volta de fins do séc. XIII. Chialà (2002: 354-7) cita três propostas para a data de tradução para o latim: Fabricius (1790-1809) considerou que a data lida por Grynaeus (1569) ${ }^{2}-1407$ - se referiria ao tradutor do texto de Isaac para o latim; Munitz (1974) defendeu ter sido na época da ocupação latina de Constantinopla (1204-1261); e Gribomont (1960: 352) aventa como tradutor Pietro de Fossombone (1255/60-1337), também conhecido como Angelo Clareno, pelo fato de a tradução latina de Isaac aparecer repetidamente ${ }^{3}$ junto à tradução da obra de João Clímaco, seguramente atribuída a Clareno. Mas Potestà (1990: 273 e 323), a partir de citação de Isaac ${ }^{4}$ na obra de Pierre de Jean Olivi (ca. 1248-1298), sugeriu que a data da tradução seja mais antiga que a de Gribomont. Considerando que a maioria dos manuscritos com a tradução latina é dos sécs. XIII a XV, que o manuscrito considerado mais antigo (cód. plut. LXXXIX/96, Bibl. Medic. Laur. de Florença) seria do séc. XIII e que a citação mais antiga em latim do texto de Isaac parece estar no Tractatus Pauperis (concluído em 1270) de John Pecham (1230-1292), Chialà (2002) propôs o séc. XIII como terminus ante quem para a tradução latina.

\footnotetext{
${ }^{2}$ Consta ao final do texto de Isaac na edição de Grynaeus (1569: 1677) a frase "Vixit Anno Domini M.CCCC.VII" bem como no cód. O.II.13 (f. 71v4) da Universidade da Basiléia, o que sugere ter sido este o modelo para a aquela edição, já que ambos estão vinculados à mesma cidade da Basiléia.

${ }^{3}$ Gribomont (1960: 350 e 352) cita os códs. 112 de Subiaco (Scala Paradisi de Clímaco, f. 79r; e Collationes de Isaac, f. 136r) e CCXVI [hoje desaparecido] de Assis (com a obra de Isaac, seguida da de Clímico). Pode-se agregar a essa lista o cód. 387 da Biblioteca Nacional da Portugal (do qual se falará mais diante) com Clímaco, seguido de Isaac (f. 94v).

${ }^{4}$ Trata-se do trecho "Visiones, inquit, fiunt habentibus ignitium zelum Dei honoris et de hoc seculo desperatis; qui eis perfecte abrenuntiaverunt et a cohabitatione hominum recesserunt et post Deum nudi egressi sunt, nullum a visibilibus auxilium expectantes" (Olivi, Questio octava de perfectione evangelica, ff. 173rb-va, cód. Vat. Burghes. 358), retomado por Clareno em sua Apologia [n. 136] (Doucet, 1946: 157) a partir de Olivi segundo Postestà (1990: 273), como "Visiones fiunt habentibus celum ignitium Dei honoris et laudis et de hoc seculo desperatis, qui perfecte abrenuntiaverunt et a cohabitatione hominum recesserunt et post Deum nudi egressi sunt, nullum a visibilibus auxilium expectantes". Segundo Postestà (1990: 273), Olivi, por sua vez, teria extraído essa citação da obra de John Pecham (Tractatus Pauperis, cap. 5).
} 
Ainda que 68 dos 82 capítulos da Primeira Parte tenham sido traduzidos para o grego, apenas 26 desses 68 foram traduzidos para o latim. Já na tradição grega se agregaram ao texto de Isaac quatro capítulos de João de Dalyata (ca. 690 - ca. 780) e uma carta de Filoxeno (ca. 450-523) a Patrício. Desses cinco textos, apenas dois de Dalyata passaram para a tradição latina (caps. 17 e 18 na tradição grega antiga). A esses 28 capítulos (26 de Isaac mais 2 de Dalyata) se agregou à tradição latina um apêndice de origem variada ${ }^{5}$ (ora como capítulo autônomo ora como parágrafo final de capítulo) e todo esse conjunto de 29 capítulos é o que é acabou por circular sob o título Livro de Isaac, dentre outras denominações, como será mencionado mais adiante.

\section{TRADIÇÃO LATINA DO LIVRO DE ISAAC}

A tradição latina do Livro de Isaac está atualmente preservada em um conjunto extenso de testemunhos manuscritos e de edições impressas. Cambraia \& Laranjeira (2010: 13-16) apuraram a existência de 95 testemunhos manuscritos latinos distribuídos por 13 diferentes países; além de mais 8 com paradeiro desconhecido. A esses, pode-se aqui acrescentar o ms. de origem italiana TM675, s. XIII.2, ff. 1-64, disponível atualmente para compra no estabelecimento francês Les Enluminures. Além dos testemunhos manuscritos, Cambraia \& Laranjeira (2010: 13-16) informam que a tradição latina do Livro de Isaac conta também com 12 edições impresas.

Considerando a abundância de testemunhos com a tradução latina da obra de Isaac de Nínive, impõe-se aqui, em nome da exeqüibilidade, a escolha de apenas alguns desses testemunhos para a comparação com a tradição indireta. Há cinco que merecem especial atenção: Bibl. Pinacoteca Accademia Ambrosiana (Milão), A 49 sup., s. XIII, ff. $1^{\mathrm{r}}-75^{\mathrm{V}}[=\mathrm{LMi}]$; Bibl. Med. Laur. (Florença), Plut. LXXXIX/96, s. XIII, ff. 1-47 [= LF]; Bibl. Città di Arezzo (Arezzo), 311, s. XIII ex.-XIV in., ff. 306 ${ }^{\mathrm{r}}-3 \mathrm{1}^{\mathrm{v}}\left[=\mathrm{LA}\right.$; ; Bibl. S. Convento (Assis), ${ }^{6}$

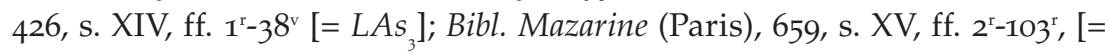
$\mathrm{LPm}$ ]. Os quatro primeiros estão dentre os mais antigos a que se obteve acesso até o presente e o quinto pertenceu à biblioteca da Abadia de Saint Victor de Paris, cidade em que Pecham lecionou teologia entre 1269 (ano em que teria dado início à redação de seu Tractatus Pauperis) e 1272.

\footnotetext{
${ }^{5}$ Trata-se de um conjunto de frases extraídas de diferentes obras: Epístolas, de São Jerônimo; Diálogos, de São Gregório; e Sentenças; de Santo Isidoro.

${ }^{6}$ Trata-se ademais de testemunho pertencente a uma instituição de referência para a Ordem dos Franciscanos, ordem a que pertenceu Pecham.
} 


\section{O TRACTATUS PAUPERIS DE JOHN PECHAM}

John Pecham nasceu em Patcham (região de Sussex) no sudeste da Inglaterra por volta de 1230-1240, foi educado no Priorado de Lewes, entrou para a Ordem Franciscana em fins da segunda metade do séc. XIII, estudou e lecionou na Universidade de Paris entre 1269 e 1272, lecionou em Oxford entre 1272 e 1275, foi Arcebispo de Canterbury entre 1279 e 1292, ano em que faleceu.

Produziu uma vasta obra, 7 mas interessa aqui o chamado Tractatus Pauperis contra insipientem novellarum haeresum confictorem circa Evangelicam perfectionem, também nomeado como Tractatus de Perfectione Evangelica ou Libellus de Paupertate, cujo incipit é "Quis dabit capiti". Essa obra teria sido escrita entre 1269 e 1270 (quando estava em Paris), é constituído de 16 capítulos e foi composto em defesa do voto de pobreza.

Não há até o momento uma edição crítica integral do tratado de Pecham, mas capítulos seus aparecem editados em diferentes publicações: caps. 1-6, Van den Wyngaert (1925: 5-86); caps. 7-9, Delorme (1932: 54-62 e 164-193); caps. 10 e 16, com excertos dos caps. 7-9, 11, 12 e 15, Kingsford, Little \& Tocco (1910: 27-90); caps. 11-14, Delorme (1944: 90-120); cap. 15, Delorme (1925: 79-88).

A edição de Kingsford, Little \& Tocco (1910) baseia-se em cinco testemunhos (sendo o primeiro o testemunho-base e os dois últimos testemunhos apenas eventualmente consultados):

(i) Oxford, Corpus Christi College, 182, ff. 1-36, fins do séc. XIII ou princ. do séc. XIV;

(ii) Vaticano, Biblioteca do Vaticano, Borghese 161, ff. 59-182v, ca. 1300;

(iii) Vaticano, Biblioteca do Vaticano, Lat. 1013, ca. 1300;

(iv) Florença, Laurentiana (Ex Bibl. S. Crucis), Plut. XXXI sin. 3;

(v) Londres, British Museum, Add. 36984, fins do séc. XIV.

A edição de Van den Wyngaert (1925) leva em conta quatro dos testemunhos usados na edição de Kingsford, Little \& Tocco (1910), sendo o primeiro igualmente tomado como testemunho-base. Embora não tenha consultado o de Londres, consultou um outro testemunho:

(vi) Florença, Laurentiana (Ex Bibl. S. Crucis), Plut. XXXVI dext. 12. 
A edição de Delorme (1932) baseia-se nos dois testemunhos de Florença - cf. testemunhos em (iv) e (vi) acima. Já a edição de Delorme (1944) toma igualmente esses dois testemunhos como base mas foi realizada com colação completa do testemunho em (ii) e parcial dos testemunhos em (iii) acima e em (vii) abaixo:

(vii) Vaticano, Biblioteca do Vaticano, Lat. 1014.

Infelizmente os editores não fizeram uso consensual de siglas. Uma vez que a análise do presente trabalho levará em conta as diferentes edições, é necessário padronizar o uso das siglas, tentando manter sempre que possível os casos em que não há discordância entre os editores. Como resultado, propõe-se um sistema de siglas privilegiando a primeira atribuição de sigla para cada testemunho nas referidas edições (ver quadro ao lado). ${ }^{8}$

\section{CONFRONTOS ENTRE TRADIÇÃO DIRETA E INDIRETA DO LIVRO DE ISAAC}

A presença de citações de Isaac de Nínive no Tractatus Pauperis de John Pecham chamou a atenção de Potestà (1990: 270-78), que esclarece que, na seção do apêndice da Apologia de Angelo Clareno dedicada à pobreza, Doucet, seu editor, indica que dois trechos teriam sido extraídos do De perfectione evangelica de Pecham, mas, diante de um exame minucioso, Potestá conclui que na verdade derivam de citação na Quaestio nona de perfectione evangelica de Pierre de Jean Olivi, ou seja, Clareno citou Pecham através de consulta a Olivi.

O exame das citações de Isaac em Pecham é interessante porque possibilita, por um lado, estabelecer a forma genuína do texto de Pecham, que, como se verá mais adiante, também apresenta variantes entre seus testemunhos, mas também porque, por outro lado, permite identificar qual dos testemunhos com a tradução latina de Isaac está mais próximo do testemunho que teria consultado Pecham e, provavelmente, estaria mais próximo da forma original dessa tradução. Enfim, a concordância entre as variantes

${ }^{8}$ Além desses testemunhos, a obra em questão também está presente nos seguintes manuscritos: Paris, Bibl. S. Victor (Montfaucon Bibl. Bibl. ii. 1372); Ravenna, Bibl. Classens. 139. 3. A e Bibl. Classens. 298; Praga, Bibl. Univers. v. D. 10, f. 147; Wolfenbuttel, Bibl. Ducal. 550; Berlin, Bibl. Reg. lat. th. fol. 225; Munique, Bibl. Reg. lat. 23455 zz. 445; Brunswick, Bibl. Civit. 140; Bruxelas, Bibl. Reg. 1677. O cap. X encontra-se como Apologia super regulam S. Francisci nos manuscritos: Durham, Cathedral Library B. iii. 8; Besançon, Bibl. Civit. i. 19; e Trèves, 776 Miscell. (Kingsford, Little \& Tocco 1910: 5-6, e Van den Wyngaert 1925: 1). 
CÉSAR NARDELLI CAMBRAIA

\begin{tabular}{|c|c|c|c|c|c|c|c|c|}
\hline 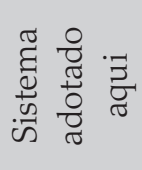 & 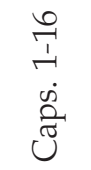 & 0 & $\infty$ & $>$ & $\checkmark$ & $\sum$ & $v^{2}$ & $P^{N}$ \\
\hline 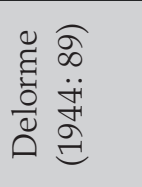 & $\begin{array}{l}\vec{H} \\
\overrightarrow{1} \\
\vec{F} \\
\dot{n} \\
\overrightarrow{\tilde{U}}\end{array}$ & & $\mathbb{I}$ & $>$ & $\nabla$ & & $\infty$ & $S$ \\
\hline 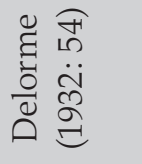 & $\begin{array}{l}a \\
\hat{1} \\
\dot{0} \\
\tilde{u}\end{array}$ & & 1 & $\mid$ & 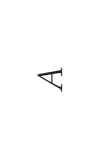 & & $\infty$ & 1 \\
\hline 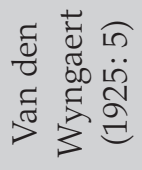 & $\begin{array}{l}p \\
1 \\
\dot{1} \\
\dot{0} \\
\tilde{U}\end{array}$ & 0 & $\infty$ & $\nabla$ & H & & - & $\mid$ \\
\hline 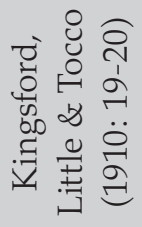 & 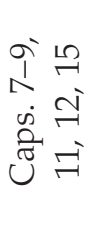 & 0 & $\infty$ & $>$ & -1 & $\sum$ & | & $\mid$ \\
\hline & & 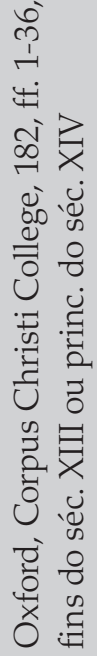 & 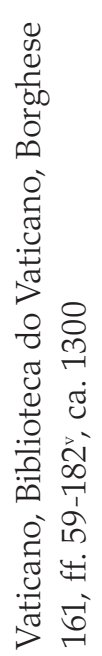 & 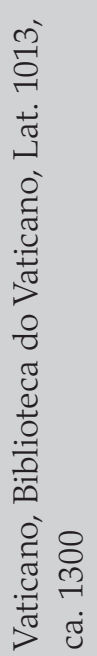 & 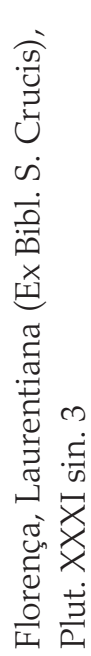 & 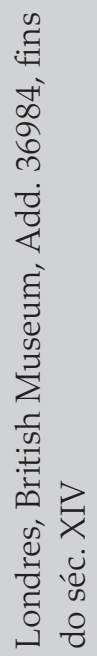 & 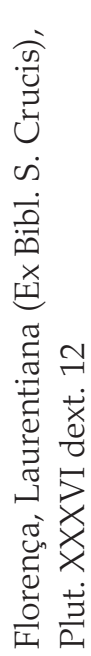 & 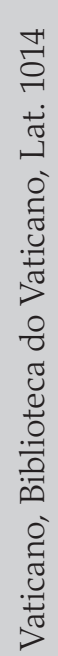 \\
\hline
\end{tabular}


da tradição indireta (as citações em Pecham) e as da tradição direta (os testemunhos da tradução latina de Isaac) fixam simultaneamente a forma que mais provavelmente seria a genuína em ambas.

Um primeiro aspecto de interesse quanto às citações de Isaac em Pecham diz respeito aos vários títulos com que a obra de Isaac circulou em latim. Como exemplo, têm-se as seguintes formas nos cinco testemunhos latinos eleitos para o presente estudo:

LMi: Liber beati Ysaac syri viri regiliosi compostus in sermonibus quadraginta de contemplationis perfectione (f. 1r1-2)

LF: $\quad$ Liber Hisaac abbatis de Syria (f. 1r1)

LA: Liber beati Ysaac abbatis Syrie de [contemp] tu mundi et de contemplationis perfectione (f. 306r1-2)

LAs: Liber qui vocatur Ysaac cujus vitam comendat Gregorius (f. 25r1)

LPm: [I]saac de contemplatione (f. 1ri-2)

Liber Isaac abbatis Syrie de perfectione contemplationis (f. 102V2O-21)

Nas citações na obra de Pecham, a obra de Isaac é consistentente intitulada De perfectione contemplationis (Van den Wyngaert (1925: 9, 11, 14, 64, 73, 74 e 78) e Delorme (1944: 90, 93, 94, 95, 102, 102 ${ }^{\text {bis }}$ e 104)), exceto por uma ocorrência como apenas De perfectione (Delorme 1944: 109). Este primeiro confronto entre tradição direta e indireta sugere que o título original com que a obra de Isaac circulou tenha sido, de fato, De perfectione contemplationis ou De contemplationis perfectione, pois assim aparece na obra de Pecham (concluída em 1270) e também em dois dos testemunhos mais antigos da tradição direta ( $L M i$ e $L A$ ). É de notar que a forma do título de $L P m$ é mais próxima da tradição indireta, o que pode estar indicando que esse testemunho que pertenceu à Abadia de Saint Victor de Paris seja o mais próximo do consultado por Pecham, que estaria em Paris quando escreveu o seu Tractatus.

Um segundo aspecto de interesse quanto às citações de Isaac em Pecham diz respeito às freqüentes redivisões dos capítulos da obra de Isaac. Como exemplo, tem-se a seguinte quantidade de capítulos nos cinco testemunhos latinos eleitos para o presente estudo: $L M i, 34$ caps.; $L F, 71$ caps.; $L A, 38$ caps.; $L A s s^{\prime}, 37$ caps. (+ 1 apêndice); $L P m, 44$ caps. ${ }^{9}$ Em duas citaçoes na obra de Pecham, indica-se o livro ou tratado de onde foram retiradas: tal é o caso da citação iniciada por Visiones fiunt, que, segundo assinalado, teria sido extraída do "tractatu 5" (Van den Wyngaert 1925: 64); e da citação

\footnotetext{
${ }^{9}$ Falta aos testemunhos $L A s_{3}$ e $L F$ um capítulo genuíno, que se inicia por Continuum silentium, que corresponde ao cap. 25 em $L M i$, cap. 24 em LA e cap. 28 em $L P m$.
} 
iniciada por Cum volveris, que, segundo assinalado, teria sido extraída do "libro I" (Delorme 1944: 93), mas com a variante "II" nos testemunhos B e $L_{2}$. Nos cinco testemunhos da tradição direta considerados aqui, a posição dessas duas citações por capítulo é a seguinte, respectivamente: $L M i$, cap. 5 e 2; $L F$, cap. 4 (27) e 2 (12); ${ }^{10} L A$, cap. 4 e 1 ; ${ }^{11} L A s$, cap. 5 e 2 ; e $L P m$, cap. 7 e 2. Este segundo confronto entre tradição direta e indireta sugere que a divisão original está melhor preservada, no primeiro caso, em $L M i$ e $L A s_{3^{\prime}}$ testemunhos cuja divisão é compatível com a localização da citação informada por Pecham. No segundo caso, a situação é mais complexa, pois a variante do texto de Pecham presente no testemunho $\mathrm{L}$ da é compatível com $L A$, mas a variante presente nos testemunhos $B$ e $L_{2}$ é compatível com $L M i$ e $L A s_{3^{\prime}}$ como no primeiro caso. Diante disso, pode-se inferir que, na verdade, seria a variante não-adotada pelo editor de Pecham (no caso, Delorme) a que é genuína. Neste caso, é a tradição direta que permite retificar a tradição indireta.

$\mathrm{O}$ terceiro aspecto de interesse quanto às citações de Isaac em Pecham, que é o principal aqui, é o texto das próprias citações. A leitura dos dezesseis ${ }^{12}$ capítulos do Tractatus Pauperis de Pecham permitiu identificar 32 citações de Isaac de Nínive, ${ }^{13}$ embora algumas delas sejam repetições: desconsiderando as repetições, verifica-se a presença de 27 diferentes trechos da obra de Isaac de Nínive na obra de Pecham. As citações concentram-se em certos capítulos do Tractatus: cap. $1=6$ cits.; cap. $5=1$ cit.; cap. $6=4$ cits.; cap. $7=1$ cit.; cap. $11=6$ cits. e cap. $12=13$ cits. A seguir apresenta-se uma comparação entre as variantes da tradição indireta e da tradição direta. ${ }^{14}$

Citação $1 .{ }^{15}$ Majus omnibus est ut causas pugne longius prorogemus, quamquam ex hoc corpus angustiam patiatur, ne cum supervenerit necessitas, ruinam propter

\footnotetext{
${ }^{10}$ LF apresenta uma numeração confusa: a numeração explícita vai apenas até o número 4, embora na extensão coberta por esses 4 capítulos haja 27 subdivisões; depois aparecem apenas as subdivisões (44 delas). Uniformizando-se o critérios de descrição com base nas subdivisões, que aparece ao longo de ttoda a obra, seriam, na verdade, no conjunto 71 capítulos.

${ }^{11}$ Neste caso, trata-se dos capítulos que receberam respectivamente a numeração 4 e 1 mas são o quinto e o segundo da seqüência, já que o primeiro não recebeu numeração.

${ }_{12} \mathrm{O}$ cap. 15 foi lido apenas através dos excertos presentes em Kingsford, Little \& Tocco (1910: 60-3), pois não foi possível ter acesso a Delorme (1925: 79-88).

${ }^{13}$ É interessante notar que, para Pecham, o Isaac que tanto cita seria o do qual fala São Gregório em seus Diálogos (Van den Wyngaert 1925: 65 e 78), mas o citado por Gregório é, na verdade, o Isaac de Antióquia, e não o de Nínive.

${ }^{14}$ Não serão informadas variantes puramente formais, tais como esurientes $x$ exurientes, potius $x$ pocius, laetitia $x$ leticia, etc.

${ }^{15}$ As citações transcritas a seguir foram extraídas de Van den Wyngaert (1925), Delorme (1932) e Delorme (1944).
} 
propinquitatem incurrat. (Pecham, cap. 1, p. 9; Migne, cap. 18, col. 841) / Maius omnibus est ut causas pugnae longius prolongemus a nobis, quamquam ex hoc corpus angustiam patiatur, ne, cum supervenerit necessitas, ruinam propter propinquitatem incurrat. (Pecham, cap. 11, p. 94, 1s. 153-156; Migne, cap. 18, col. 841).

a. Variantes da tradição indireta: cap. 1, quamquam] quamquam autem $L$; supervenerit] venerit $L_{2}$ / cap. 11, omnibus] om. $L_{2} ;$ prolongemus] prorogemus $B V L_{2}$; propinquitatem] iniquitatem $L_{2}$.

b. Variantes da tradição direta [LMi (26v8-11), $L A$ (330r3-6), $L A s_{3}$ (46v11-13), $L P m$ (35r24-35v2) e $L F$ (19r13-16)]: Majus/Maius] Maius autem $L M i L A L A s_{3} L P m$ $L F$; causas] causam $L A$; prorogemus/prolongemus a nobis] prorogemus $L M i$ $L P m$, proregemus $L A$, prorogemus (modificado para prologemus) a nobis (sobrescrito) $L A s_{3^{\prime}}$ prolongemus a nobis $L F$; quamquam ex hoc corpus] quamvis corpus ex hoc $L A s_{3}$; ne] quia timor est ne $L M i L A L A s_{3} L P m$, quia timeo ne $L F$; necessitas] occasio et necessitas $L F$; ruinam] ruinam eorum $L F$, in ruinam $L P m$; propinquitatem] propinquitatem eorum (eorum sobrescrito) $L A s_{3}$; incurrat] incurras $L F$.

c. Comentários: No primeiro lugar-crítico ${ }^{16}$ da tradição indireta no cap. 11, a variante adotada (omnibus) coincide com a dos cinco testemunhos da tradição direta ( $L M i, L A, L A s_{3^{\prime}}, L P m$ e $\left.L F\right)$, sugerindo ser a genuína. No segundo lugar-crítico, há duas variantes: prorogemus, no cap. 1, sem variação entre os testemunhos desse capítulo; e prolongemus a nobis, no cap. 11, com a variante prorogemus em $B, V$ e $L_{2}$. Curiosamente, o editor do cap. 11 (Delorme, 1944) parece não ter-se dado conta da existência dessa mesma citação no cap. 1, onde a forma única era prorogemus, justamente a variante que ele não adotou no cap. 11. Uma vez que a variante prorogemus está, na tradição direta, em $L M i$ e $L P m$, além de aparecer ligeiramente deturpada em $L A$ como proregemus e ainda como forma primitiva em $L A s_{3}$ (tendo sofrido uma modificação incompleta para prologemus, em que ficou faltando um - $n$-, provavelmente por atração exercida pela palavra imediatamente anterior: longius), deve-se considerá-la como a genuína: supreende nesse caso que o editor do cap. 11 tenha ficado com prolongemus, justamente a menos frequente na tradição indireta. No terceiro e quarto lugares-críticos da tradição indireta, as variantes adotadas no cap. 1 (respectivamente, quamquam e supervenerit) coincidem as dos cinco testemunhos da tradição direta, sugerindo serem as genuínas. No quinto lugar-crítico da tradição indireta, a variante adotada no cap. 11 (propinquitatem) coincide com os cinco testemunhos da tradição direta, sugerindo ser a genuína.

\footnotetext{
${ }^{16}$ Nos comentários a ordem dos lugares-críticos baseia-se na ordem em que aparecem na citação, e não na ordem em que aparecem nos itens $a$ e $b$, que apresentam as variantes.
} 
Citação 2. Munda tibi cellam a delitiis et superfluitatibus, quia hoc adducet te ad abstinentiam invitum etiam et nolentem; | raritas rerum docet abstinere, quia || cum opportunitatem rerum accipimus, nosmetipsos non possumus continere. (Pecham, [citação completa] ${ }^{17}$ cap. 1, p. 11, e cap. 6, p. 83; [citação a partir da barra vertical simples] cap. 7, p. 59; [citação a partir da barra vertical dupla] cap. 11, p. 94, 1s. 160-161; Migne, cap. 9, col. 819)

a. Variantes da tradição indireta: cap. 1, quia ${ }^{1}$ ] et $L_{2}$; cap. 6, etiam (no cap. 6, não há et depois)] et $O B$.

b. Variantes na tradição direta [LMi (7r7-11), LA (311r30-311v4), LAs 3 (29v2230r3), LPm (9r10-15) e LF (5r1-4)]: Munda] Munda igitur LF; delitiis et superfluitatibus] superfluitatibus et delitiis $L F$; hoc adducet te] hoc adducit te $L M i$ $L A$, hoc aducit te $L A s_{3^{\prime}}$, adducet te hoc $L P m$, hec te adducet $L F$; abstinentiam] abstinentia $L P m$; invitum etiam] etiam invitum $L P m L F$; nolentem] renitentem $L P m$, nolentem id est defectio $L F$; Raritas] Caritas vel carentia $L A$, Karitas (com remissão a id est carentia na margem superior) $L A s_{3}$; docet] docet hominem LMi $L A \mathrm{LAs}_{3} L P m$ LF; opportunitatem rerum accipimus] accipimus rerum oportunitatem $L A$, oportunitatem rerum acceperimus $L F$; nosmetipsos non possumus] non poss $<\mathrm{u}>\mathrm{m}<\mathrm{u}>$ s nosmetipsos $L A$.

c. Comentários: No primeiro lugar-crítico da tradição indireta, a variante adotada no cap. 1 (quia) coincide com os cinco testemunhos da tradição direta, sugerindo ser a genuína. No segundo lugar-crítico da tradição indireta, a variante adotada no cap. 1 (etiam et) coincide com três testemunhos da tradição direta ( $L M i, L A e L A s_{3}$ ), sugerindo ser a genuína; enquanto as no cap. 6 (etiam e et) não coincidem com nenhum dos testemunhos diretos, sendo provavelmente não-genuínas.

Citação 3. Qui non se elongat voluntarie a causis vitiorum, invitus trahitur a peccato. Hec enim sunt cause peccati: vinum, mulieres, divicie et prospera corporis habitudo. Non quod hec naturaliter sint peccatum, sed quia natura facile declinat ad peccati passiones propter ipsa. (Pecham, cap. 1, p. 11-12, Migne, cap. 11, col. 821)

a. Variantes da tradição indireta: enim] nim $L_{2}$; naturaliter] rationaliter $L$; natura] rationaliter $L$.

b. Variantes na tradição direta [LMi (8v21-26), LA (313r7-12), LAs 3 (31r14-17), LPm (11r19-24) e $L F$ (6r10-13)]: se elongat] elongat se $L M i L A L A s_{3} L P m L F$; voluntarie a causis vitiorum] a causis vitiorum voluntarie $L M i L A L A s_{3} L P m L F$; a peccato] ad peccata $L A$, ad peccatum $L F$; enim sunt] sunt enim $L M i L A L A s_{3}$ $L P m$, sunt $L F$; vinum mulieres divicie] mulieres divicie vinum] $L P m$; divicie

\footnotetext{
${ }^{17}$ Este trecho à p. 83 difere do à p. 11 pela presença de etiam naquele mas de etiam et neste.
} 
et prospera corporis habitudo] prospera corporis habitudo et divicie $L F$; et] ac $L M i L A L A s_{3} L P m L F$; hec] om. $L A$; naturaliter sint] sint naturaliter $L F$; quia natura facile declinat] per hec declinatur $L F$; peccati passiones] passiones peccati $L F$; propter ipsa] per ipsa $L M i L A s_{3}, o m$. $L F$.

c. Comentários: No primeiro lugar-crítico da tradição indireta, a variante adotada (enim) difere da outra por faltar apenas ume, fato pouco relevante, já que é um erro óbvio. No segundo e terceiro lugares-críticos da tradição indireta, as variantes adotadas (respectivamente, naturaliter e natura) coincidem as dos cinco testemunhos da tradição direta, sugerindo serem as genuínas.

Citação 4. Quibus mundus mortuus est, hii sustinent adversitates gaudenter. Qui vero vivit hujusmodi nequeunt injuriam sustinere sed a vana gloria moti irati turbantur seu etiam a tristitia occupantur. (Pecham, cap. 1, p. 13, Migne, cap. 13, col. 828)

a. Variantes da tradição indireta: Qui] Quibus $B L L_{2}$; hujusmodi] om. $B L_{2}$; irati] om. $L$; seu etiam a] sive et $L$.

b. Variantes na tradição direta [LMi (14v26-15r1), LA (319v17-21), LAs 3 (36r14-16), $L P m$ (19r10-14) e LF (11r2-3/5-7)]: mundus mortuus est] est mundus mortuus $L F$; adversitates] adversitatem $L F$; Qui] Quibus $L M i L A L A s_{3} L P m$, Et quibus $L F$; vero vivit] mundus vivit $L M i L A s_{3} L P m$, non est mortuus $L F$; hujusmodi] hii $L M i L A L A s_{3} L P m$, om. $L F$; injuriam] injurias $L F$; irati] $L P m$, ira $L F$; a] om. $L A$.

c. Comentários: No primeiro lugar-crítico da tradição indireta, a variante adotada (Qui) diverge em relação aos cinco testemunhos da tradição direta, sugerindo ser a genuína a outra (Quibus), presente, a propósito, em três testemunhos da tradição indireta $\left(B, L\right.$ e $\left.L_{2}\right)$. No segundo lugar-crítico da tradição indireta, a variante adotada (hujusmodi) diverge em relação aos cinco testemunhos da tradição direta, sendo igualmente divergente a outra existente na tradição indireta (a omissão dessa palavra): aparentemente o erro na tradição parece decorrer de uma leitura de hii (presente na tradição direta) como abreviatura para hujusmodi, mas, como o editor do texto de Pecham não informa onde desenvolveu abreviaturas, não é possível saber se esse erro remonta à própria tradição direta, à interpretação da tradição direta por Pecham ou ainda à interpretação da tradição indireta pelo editor do texto de Pecham. No terceiro lugar-crítico da tradição indireta, a variante adotada (irati) coincide com três testemunhos da tradição direta $\left(L M i, L A\right.$ e $\left.L A s_{3}\right)$, sugerindo ser a genuína. No quarto lugar-crítico da tradição indireta, a variante adotada (seu etiam a) coincide com quatro testemunhos da tradição direta ( $L M i, L A s_{3^{\prime}} L P m$ e $L F)$, sugerindo ser a genuína. 
Citação 5. Verbum durum sustinens homo scienter absque iniquitate que precesserit in ipso contra loquentem, coronam spineam capiti suo superimponit. (Pecham, cap. 1, p. 14, Migne, cap. 1, col. 812)

a. Variantes da tradição indireta: scienter absque iniquitate] iniquitate absque scienter $O$, absque iniquitate $L_{2}$.

b. Variantes na tradição direta [LMi (1r22-1v2), LA (306r23-26), LAs ${ }_{3}$ (25r15-17), $L P m$ (2r25-2v1) e LF (1r17-19)]: scienter] sciens $L F$; que] quod $L M i$; in] ab $L M i$ $L A L A s_{3} L P m L F$; ipso] illo $L F$; coronam] coronam quidem $L M i L A L A s_{3} L P m$ $L F$; superimponit] superponit $L P m L F$.

c. Comentários: No único lugar-crítico da tradição indireta, a variante adotada (scienter absque iniquitate) coincide com quatro testemunhos da tradição direta $\left(L M i, L A, L A s_{3}\right.$ e $\left.L P m\right)$, sugerindo ser a genuína.

Citação 6. Humilitatis est perferre accusationes falsas cum gaudio sustinere. | Qui in veritate humilis est patiendo injuriam non turbatur nec excusat se super re in qua injuriam est perpessus sed veniam petit. (Pecham, cap. 1, p. 14, Migne, cap. 15, col. 831 [antes da barra vertical] e cap. 16, col. 831-832 [depois da barra vertical])

a. Variantes da tradição indireta: Humilitatis est preferre accusationes falsas] ${ }^{18}$ om. $O$; falsas] om. $L_{2}$; Qui] Qui enim $B$; injuriam $\left.{ }^{2}\right]$ injuria $O$.

b. Variantesna tradição direta [LMi(18r17-18/18r27-18v3), LA (321v23-24/322r4-8), $L A s_{3}$ (38v20-21/39r5-7), $L P m$ (23v17-19/24r5-10) e $L F$ (13r10-11/13r19-22)]: est perferre] perfectio est $L M i L A L A s_{3} L P m L F$; turbatur] conturbatur $L A s_{3}$; re] rem $L F$; injuriam $\left.{ }^{2}\right]$ injuria $L F$; perpessus] passus vel perpessus $L P m$; sed] sed recipit accusationem ut veritatem nec sollicitus est suggerere hominibus quod sit accusatus sed ${ }^{19} L M i L A L A s_{3^{\prime}}$, sed recipit accusationem ut veritatem nec est sollicitus suggerere hominibus quod sit accusatus sed LPm.

c. Comentários: No primeiro lugar-crítico da tradição indireta, tanto a variante adotada quando a segunda existente divergem em relação aos cinco testemunhos da tradição direta, sugerindo não existir na tradição indireta a forma genuína: a origem do erro da variante adotada (mais próxima à genuína do que a variante de $O$ ) parece ser uma má leitura de abreviatura para perfectio, interpretada como perferre. No segundo e terceiro lugares-críticos da tradição

${ }^{18}$ Trata-se de salto-bordão, pois o trecho está entre duas ocorrências de falsas no texto de Pecham (... accusationes falsas patienter suffere. Unde Ysaac in eodem libro: Humilitatis est preferre accusationes falsas...)

${ }^{19}$ Como a diferença entre a tradição direta e indireta neste ponto está entre duas ocorrências da conjunção sed, há a possibilidade de que se trate de um outro salto-bordão, que pode remontar ao testemunho da tradição direta consultado por Pecham, à transcrição do próprio Pecham ou ainda à transcrição do editor de Pecham. 
indireta, as variantes adotadas (respectivamente, falsas e Qui) coincidem as dos cinco testemunhos da tradição direta, sugerindo serem as genuínas. No quarto lugar-crítico da tradição indireta, a variante adotada (injuriam) coincide a de quatro testemunhos da tradição direta ( $L M i, L A, L A s_{3}$ e $\left.L P m\right)$, sugerindo ser a genuína: a presença de uma mesma variante em $O$ e em $L F$ parece ser fruto de erro poligenético, dado que a diferença em relação á genuína remota provavelmente ao esquecimento de um titulus sobre o $a$ final.

Citação 7. Quousque deferat a corde suo sollicitudinem secularium propter necessarium usum nature ac dimictat Deum curare de ipsis, spiritualis ebrietas in ipso non movebitur et consolationem illam non habebit, de qua erat Apostolus consolatus. (Pecham, cap. 5, p. 64, Migne, cap. 10 col. 820)

a. Variantes da tradição indireta: deferat] destruat $B$.

b. Variantes na tradição direta [LMi (8r16-20), LA (312v5-10), LAs 3 (30v19-22), LPm (10v8-13) e LF (5v16-19)]: deferat] destruat LMi LA LAs ${ }_{3} L P m L F$; a] in LF; propter] preter $L M i L A L A s_{3} L P m L F$; usum nature] nature usum $L A$; ipsis] ipsis iter $L A$, se $L P m$; non movebitur] movebitur $L A$, movebitur non $L F$; habebit] sentiet LMi LA LAs ${ }_{3} L P m L F$.

c. Comentários: No único lugar-crítico da tradição indireta, a variante adotada (deferat) diverge em relação aos cinco testemunhos da tradição direta, sugerindo ser a genuína a outra (destruat), presente, a propósito, em um testemunho da tradição indireta $(B)$. Considerando as variantes da tradição direta, verifica-se que $L F$ e $L A$ são os testemunhos cujas variantes mais se afastam do texto da citação indireta.

Citação 8. Visiones fiunt habentibus zelum ignitium Dei et de hoc seculo desperatis, qui ei perfecte abrenuntiaverunt et a cohabitatione hominum recesserunt et post Deum egressi sunt nudi, nullum a visibilibus auxilium expectantes, super quos irruit aliquando fortitudo propter sollitudinem, et circumdat eos periculum mortis ex fame vel infirmitate aut ex aliquo incursu et tribulatione, ita ut, appropinquent desperationi. Consolationes ergo que fiunt talibus non fiunt illis qui eos superant in labore, quia quanto quis habet consolationem humanam ab aliquo visibilium, tanto hujusmodi consolationes non fiunt. (Pecham, cap. 5, p. 64; Migne, cap. 18, col. 845) / Quod visiones fiunt quibusdam perfecte sanctis et de hoc seculo desperatis, qui ei perfecte renuntiaverunt et post Deum nudi egressi sunt nullum a visibilibus auxilium expectantes. (Pecham, cap. 6, p. 73; Migne, cap. 18, col. 845)

a. Variantes da tradição indireta: cap. 5, fortitudo] formido $L$, sollicitudo $L_{2}$; quis] om. L / cap. 6, Quod] om. O; quibusdam] quidem $O$; sunt] om. O.

b. Variantes na tradição direta [LMi (29v22-30r5), LA (333r2-12), LAs 3 (49v8-15), LPm (40r18-40v6) e LF (5v16-19)]: Visiones fiunt] quibusdam perfecte sanctis 
vel $L M i L A s_{3} L P m L F$, quibusdam perfecte scientie vel $L A$; ignitium] ignitum $L M i L A L A s_{3} L P m$, ingnitum $L F$; Dei] fidei $L F$; desperatis] desperati $L F$; ei] om. LMi $L A L A s_{3} L P m L F$; egressi sunt nudi] nudi egressi sunt $L M i L A L A s_{3} L P m$ $L F$; nullum] in terra $L A$; a visibilibus auxilium] auxilium a visibilibus $L F$; visibilibus] visi<bili>bus $L P m$; super] sunt $L A$; irruit] irruint $L F$; aliquando] om. $L M i L A L A s_{3} L P m$; fortitudo] formido $L M i L A L A s_{3} L P m$; et] vel $L M i L A L A s_{3}$ $L P m$, vel quando $L F$; infirmitate] ex infirmitate $L M i L A L A s_{3} L P m$; aut] aut etiam $L M i L A L A s_{3} L P m$; aliquo] alio $L F$; et] seu $L A$, vel $L F$; appropinquent] quasi appropinquent $L M i L A L A s_{3} L P m L F$; Consolationes] Consolationum LMi LA LPm; non] nec $L M i L A L A s_{3} L P m L F$; superant] superarent $L F$; quia] prima causa hec est $L M i L A L A s_{3}$, prima causa est $L P m$, et prima causa hec est $L F$; habet] plus habet $L F$; tanto] tanto sibi $L M i L P m$, tante sibi $L F$; hujusmodi] hujus $L A L A s_{3}$; consolationes] consolationes sibi $L A s_{3} /$ Quod visiones fiunt] om. $L M i L A L A s_{3} L P m L F$; sanctis] scientie $L A$; et] habentibus zelum ignitum Dei et $L M i L A L A s_{3} L P m$, habentibus zelum ingnitum fidei et $L F$; desperatis] desperati $L F$; renuntiaverunt] abrenuntiaverunt $L A s_{3} L P m$; et] et a cohabitatione hominum recesserunt et $L M i L A L A s_{3} L P m L F$.

c. Comentários: Primeiramente é interessante notar que há cinco diferenças entre as duas citações do mesmo trecho na tradição indireta (note-se que a segunda citação repete apenas parte do início da primeira): cf. $\varnothing$ no cap. 5 $\times$ Quod no cap. 6; habentibus zelum ignitium Dei no cap. $5 \times$ quibusdam perfecte sanctis no cap. 6 ; abrenuntiaverunt no cap. $5 \times$ renuntiaverunt no cap. 6 ; et a cohabitatione hominum recesserunt no cap. $5 \times \varnothing$ no cap. 6; egressi sunt nudi no cap. $5 \times$ nudi egressi sunt no cap. 6 . No primeiro lugar-crítico da tradição indireta, a variante adotada (fortitudo) diverge em relação a quatro testemunhos da tradição direta ( $\left.L M i L A L A s_{3} L F\right)$, sugerindo ser genuína a outra (formido), mas note-se, a propósito, que a variante adotada ocorre em um dos testemunhos da tradição direta $(L P m)$, fato curioso, já que sugere o copista de $L$, da tradição indireta, teria consultado um testemunho da tradição direta com a forma genuína e copiado (caso de contaminação). No segundo lugar-crítico da tradição indireta, a variante adotada (quis) coincide com a dos cinco testemunhos da tradição direta, sugerindo ser a genuína. No quatro lugar-crítico da tradição indireta, a variante adotada ( $Q u o d)$ diverge em relação a dos cinco testemunhos da tradição direta, sugerindo ser a genuína a outra (a omissão de quod). No quinto lugar-crítico da tradição indireta, a variante adotada (quibusdam) coincide com a dos cinco testemunhos da tradição direta, sugerindo ser a genuína. No sexto lugar-crítico da tradição indireta, a variante adotada (sunt) coincide com a de quatro testemunhos da tradição direta ( $L M i, L A s_{3^{\prime}}$ $L P m$ e $L F)$, sugerindo ser a genuína.

Citação 9. Anticipa solvere omnem colligationem extrinsecam a te ipso et tunc Deo poteris colligari. (Pecham, cap. 6, p. 74, Migne, cap. 1 col. 811) 
a. Variantes da tradição indireta: a te ipso] om. $L$.

b. Variantes na tradição direta [LMi (1r5-6), LA (306r4-6), LAs 3 (25r2-3), LPm (2r3-5) e $L F$ (1r2-4)]: Anticipa] Anticipa igitur $L A s_{3} L P m$; colligationem] obligationem $L P m$; Deo] Deo corde $L M i L A L A s_{3}$; Deo poteris] poteris corde $L P m$; poteris] poteris corde $L F$.

c. Comentários: No único lugar-crítico da tradição indireta, a variante adotada (a te ipso) coincide com os cinco testemunhos da tradição direta, sugerindo ser a genuína.

Citação 10. Si posueris anime tue terminum paupertatis et per gratiam Dei fueris a sollicitudine liberatus et in tua paupertate fueris factus supra mundum, cave ne propter amorem pauperum questum diligas pro eleemosyna facienda, et ponas animum tuum in turbationem ut accipias ab aliquibus et aliis largiaris, et exceriens honorem subjectione petitionis rerum nomine aliorum, et excidas a libertate intentionis tue in sollicitudinem rerum secularium, quia gradus tuus sublimior est gradibus misericordium. Supplico tibi, ne subiciaris elemosyna similis nutrimenti puerorum. Sed solitudo perfectionis est caput. I Si res habes, semel eas disperge; quod si non habes, noli habere. (Pecham, [citação completa] cap. 6, p. 78; [citação a partir da barra simples] ${ }^{20}$ cap. 6, p. 83; Migne, cap. 9, col. 818-819)

a. Variantes da tradição indireta: et² ${ }^{2}$ vel $O$; aliquibus] aliquo $B L$.

b. Variantes na tradição direta [LMi (6v22-7r7), LA (311r18-30), LAs 3 (29v13-22), LPm (8v22-9r9) e LF (4v22-5r1)]: terminum] terminos LPm; sollicitudine] solicitudinibus $L M i L A L A s_{3} L F$; fueris factus] factus fueris $L M i L A L A s_{3} L F$, fueris $L P m$; mundum] modum $L F$; animum tuum] animam tuam $L M i L A L A s_{3} L P m$ $L F$; in] a $L P m$; turbationem] turbatione $L M i L A L P m L F$; aliquibus] aliquo $L M i L A L_{3} s_{3} L P m$, alio $L F$; et aliis] ut aliis $L F$; exceriens] extermines $L M i L A$ $L A s_{3} L P m L F$; honorem] honorem tuum $L M i L A L A s_{3} L P m L F$; libertate] libertate et nobilitate $L M i L A L A s_{3} L P m L F$; sollicitudinem] sollicitudine $L M i L A$ $L A s_{3} L P m$, sollicitudines $L F$; rerum secularium] secularium rerum $L M i L A$ $L A s_{3} L P m L F$; quia] et quia $L P m$; sublimior] om. $L P m$; gradibus] gradu $L M i$ $L A L A s_{3} L F$; misericordium] misericordum $L M i L A L A s_{3} L P m L F$; elemosyna] elemosinam $L P m$; nutrimenti] est nutrinime $L M i$, est nutrimini $L A L A s_{3} L F$, est nutrimento $L P m$; puerorum] parvulorum $L F$; solitudo] sollicitudo $L F$; res] rem $L M i L A L A s_{3}$; eas] ipsas $L M i L P m$, ipsam $L A L A s_{3}$;

c. Comentários: No primeiro lugar-crítico da tradição indireta, a variante adotada (et) coincide a dos cinco testemunhos da tradição direta, sugerindo ser a genuína. No segundo lugar-crítico da tradição indireta, a variante adotada (aliquibus) diverge em relação a quatro dos testemunhos da tradição direta

${ }^{20}$ Este trecho à p. 83 difere do à p. 78 pela ausência de quod naquele. 
( $L M i, L A, L A s_{3}$ e $\left.L P m\right)$, sugerindo ser a genuína a outra (aliquo), presente, a propósito, em dois testemunho da tradição indireta $(B$ e $L)$.

Citação 11. Si, inquit, vanam gloriam abominaberis, fuge venantes eam; fuge tam amatores rerum quam acquisitionem ipsarum; elonga teipsum a prodigis sicut a prodigalitate; fuge luxuriosos sicut luxuriam, quia ubi simplex memoria conturbat mentem, quanto magis aspectus et conversatio cum eisdem! (Pecham, cap. 11, p. 90, 1s. 26-30; Migne, cap. 13, col. 829).

a. Variantes da tradição indireta: acquisitionem] acquisitores $B$; ipsarum] earum $B$; prodigis] prodigiis $L_{2}$; ubi] vir $L_{2}$.

b. Variantes da tradição direta [LMi (16r2-7), LA (319v16-21), LAs 3 (37r9-13), LPm (20r26-20v6) e LF (11v15-19)]: inquit] om. LMi LA LAs ${ }_{3} L P m$ LF; abominaberis] abominaris $L M i L F$; venantes] vendentes $L F$; acquisitionem] acquisitores $L F$; ipsarum] earum $L F$; teipsum] te $L A$; sicut a] sicut et a $L M i$; sicut luxuriam] sicut et luxuriam $L M i L A L A s_{3} L P m$; ubi simplex] simplex ubi $L A s_{3^{\prime}}$ quam verbi simpliciter $L F$; memoria] memoria predictorum $L M i L A L F L A s_{3} L P m$.

c. Comentários: No primeiro e segundo lugares-críticos da tradição indireta, as variantes adotadas (respectivamente, acquisitionem e ipsarum) coincidem as de quatro testemunhos da tradição direta $\left(L M i, L A, L A s_{3}\right.$ e $\left.L P m\right)$, sugerindo serem as genuínas. No terceiro lugar-crítico da tradição indireta, a variante adotada (prodigis) coincide a dos cinco testemunhos da tradição direta, sugerindo ser a genuína. No terceiro lugar-crítico da tradição indireta, a variante adotada ( $u b i)$ coincide a de quatro testemunhos da tradição direta ( $L M i, L A$, $L A s_{3}$ e $\left.L P m\right)$, sugerindo ser a genuína: a origem da divergência em relação a $L_{2}$ (vir) e $L F$ (verbi) parece dever-se a problema de interpretação da abreviatura $u^{i}$, presente: ex., em $L A$ e $L A s_{3}$.

Citação 12. Cum volueris facere initium bonae operationis, ad eventuras tibi tentationes prius praepara temetipsum; nam consuetudo est inimici, ut, cum viderit aliquem incipientem bonam conversationem fide ferventi et conscientia pura, obviet ei variis et diversis tentationibus. (Pecham, cap. 11, p. 93, 1s. 138-141; Migne, cap. 12, col. 821).

a. Variantes da tradição indireta: initium] servitium $L_{2}$; cum viderit] videns $L$, cum videt $B V$; conversationem] operationem $L$; obviet] obviat $B V L L_{2}$.

b. Variantes da tradição direta [LMi (9r4-10), LA (313r18-21), $L A s_{3}(31$ r20-24), LPm (11v5-12) e $L F$ (6r18-23)]: initium bonae operationis] bone operationis initium $L F$; eventuras] ve $<\mathrm{n}>$ turas $L A$, venturas $L F L P m$ (aparentemente com apagamento de um e antes de venturas) $L A s_{3}$; tibi tentationes prius] prius tibi temptationes $L A s_{3}$ temetipsum] te ipsum $L F$; nam] ne hesites veritati Nam $L M i L A s_{3}$ $L P m$, ne hesites veritatem Nam $L A$, ne exites veritati Nam $L F$; viderit] videt 
LMi LA $\mathrm{LAs}_{3} L P m$; obviet] obviat $L M i L A L A s_{3}$; variis et diversis tentationibus] temptationibus variis et diversis $L A$, diversis et variis tentationibus $L F$.

c. Comentários: No primeiro lugar-crítico da tradição indireta, a variante adotada (initium) coincide a dos cinco testemunhos da tradição direta, sugerindo ser a genuína. No segundo lugar-crítico da tradição indireta, a variante adotada (cum viderit) diverge em relação a quatro dos testemunhos da tradição direta ( $L M i, L A, L A s_{3}$ e $\left.L P m\right)$, sugerindo ser a genuína uma outra (cum videt), presente, a propósito, em dois testemunhos da tradição indireta $(B$ e $V)$ : note-se, porém, que a variante adotada coincide com um dos testemunhos da tradição direta $(L F)$. No terceiro lugar-crítico da tradição indireta, a variante adotada (conversationem) coincide a dos cinco testemunhos da tradição direta, sugerindo ser a genuína. No quarto lugar-crítico da tradição indireta, a variante adotada (obviet) diverge em relação a três dos testemunhos da tradição direta ( $L M i, L A$ e $\left.L A s_{3}\right)$, sugerindo ser a genuína a outra (obviat), presente, a propósito, em todos os quatro testemunhos da tradição indireta $\left(B, V, L\right.$ e $\left.L_{2}\right)$ : note-se, porém, que a variante adotada coincide com a de dois testemunhos da tradição direta ( $L P m$ e $L F)$, mas esta parece ser uma lectio facilior, pois a distância entre o subordinador ut e o verbo de sua oração (obviat/obviet) deve ter levado o tradutor para o latim a esquecer-se de usar o subjuntivo, sugerindo, portanto, um "erro" tradutório, que remonta ao texto primitivo da tradução.

Citação 13. Sic dilige otium solitudinis plus quam esurientes saeculi saturare et convertere multas gentes ad agnitionem supernam et ad honorem Dei. Melius est enim a peccati vinculo solvere temetipsum quam liberare servos a servitute, potius est tibi pacificare cum anima tua in unitate Trinitatis quae in te est, scilicet corporis et animae et spiritus, quam pacificare cum doctrina tua discordes. (Pecham, cap. 11, p. 94, 1s. 174-179; Migne, cap. 3, col. 814).

a. Variantes da tradição indireta: $\mathrm{Sic}$ om. $L_{2}$; saeculi] om. $L$; saturare] saturate $V$; scilicet] videlicet $V L_{2}$.

b. Variantes da tradição direta [LMi (3r10-17), LA (307v27-308r4), LAs (26v10-14), LPm (4r25-4v6) e LF (2v1-7)]: Sic] om. $L M i$ LA LAs ${ }_{3} L P m$ LF; dilige] dilige effici $L P m$; agnitionem supernam] supernam agnitionem $L M i L A L A s_{3} L P m$; ad] om. $L A L A s_{3} L P m$; honorem] orationem $L M i$; est enim] enim est $L A s_{3^{\prime}}$ est tibi $L P m$; temetipsum] teipsum $L A s_{3}$; potius] Melius $L F ;$; est] est enim $L F$; pacificare] pascici $L M i L P m L F$, pacificum esse $L P m$; cum] in $L F$; in unitate] unitatem (à margem como correção de veritatem) LF; scilicet] videlicet LMi LA LPm; corporis

${ }^{21}$ Em LF, a frase seguinte a este período (Gregorius namque dixit Bonum est theologiam edere propter Deum, sed melius est quod semetipsum mundet quis apud Deum) aparece antecipada para antes dele. 
et animae et spiritus] corporis anime et spiritus $L M i$, anime corporis et spiritus $L A s_{3^{\prime}}$ corporis et anime et sp(iritus) $L P m$, anime et corporis $L F$; cum] om. LF. c. Comentários: No primeiro lugar-crítico da tradição indireta, a variante adotada (Sic) diverge em relação aos cinco testemunhos da tradição direta, sugerindo ser a genuína a outra (a omissão de Sic), presente, a propósito, em um testemunho da tradição indireta $\left(L_{2}\right)$. No segundo e terceiro lugares-críticos da tradição indireta, as variantes adotadas (respectivamente, saeculi e saturare) coincidem as dos cinco testemunhos da tradição direta, sugerindo serem as genuínas. No quarto lugar-crítico da tradição indireta, a variante adotada (scilicet) diverge em relação a de três testemunhos da tradição direta ( $L M i, L A$ e $L P m$ ), sugerindo ser a genuína a outra (videlicet), presente, a propósito, em dois testemunho da tradição indireta $\left(\mathrm{V}\right.$ e $\left.L_{2}\right)$ : note-se, porém, que a variante adotada coincide com dois dos testemunhos da tradição direta ( $L A s_{3}$ e $\left.L F\right)$.

Citação 14. Cum animam suam in sanctitate senserit, tunc prosit aliis et de aliis curet; nam cum inventus fuerit ab omnibus elongatus, poterit eis benefacere potius in zelo bonorum operum quam in verbis etc. (Pecham, cap. 11, p. 95, 1s. 199-201; Migne, cap. 17, col. 833)

a. Variantes da tradição indireta: sanctitate] sanitate $L$; operum] om. L; etc.] om. $B V L$.

b. Variantes da tradição direta [LMi (19v13-16), LA (323r14-18), LAs 3 (40r10-12), LPm (25v17-21) e LF (14r14-17)]: Cum] Cumque LMi LAs $L P m$ LF; animam suam] anima sua $L A$; sanctitate] sanitate $L M i L A L A s_{3} L P m L F$; tunc] tunc et (et na entrelinha) $L M i$, tunc et $L A L A s_{3} L P m L F$; curet] curam gerat $L M i L A L A s_{3}$ LPm LF; omnibus] hominibus $L A L F$; in] om. LPm; etc.] om. LMi LA LAs ${ }_{3} L P m L F$.

c. Comentários: No primeiro lugar-crítico da tradição indireta, a variante adotada (sanctitate) diverge em relação aos cinco testemunhos da tradição direta, sugerindo ser a genuína a outra (sanitate), presente, a propósito, em um testemunho da tradição indireta $(L)$. No segundo lugar-crítico da tradição indireta, a variante adotada (operum) coincide a dos cinco testemunhos da tradição direta, sugerindo ser a genuína. No terceiro lugar-crítico da tradição indireta, a variante adotada (etc.) diverge em relação aos cinco testemunhos da tradição direta, sugerindo ser a genuína a outra (a omissão de etc.), presente, a propósito, em três testemunhos da tradição indireta $(B, V$ e $L)$.

Citação 15. Dilige vilia indumenta, ut orientes in te cogitationes tuas abiicias, i.e. elationis; nam qui splendida diligit, humiles cogitationes habere non potest, quia cor exterioribus figurationibus conformatur. (Pecham, cap. 12, ls. 103-105; Migne, cap. 2, col. 814). 
a. Variantes da tradição indireta: tuas] om. $B L_{2}$; figurationibus] configurationibus $L_{2}$.

b. Variantes da tradição direta [LMi (2v13-17), LA (307v4-7), $L A s_{3}(26 \mathrm{r} 17-19), L P m$ (3v22-27) e $L F$ (2r14-16)]: indumenta] vestimenta $L F$; tuas] om. LMi LA $L A s_{3}$ $L P m L F$; abiicias i.e. elationis] id est elationis abicias $L F$; diligit] dilligunt $L A$; humiles cogitationes habere non potest] non possunt humilles habere cogitationes $L A$, humiles habere cogitationes non potest $L P m$; figurationibus] (cogitationibus riscado) figurationibus $L A s_{3}$.

c. Comentários: No primeiro lugar-crítico da tradição indireta, a variante adotada (tuas) diverge em relação aos cinco testemunhos da tradição direta, sugerindo ser a genuína a outra (a omissão de tuas), presente, a propósito, em dois testemunhos da tradição indireta $\left(B\right.$ e $\left.L_{2}\right)$. No segundo lugar-crítico da tradição indireta, a variante adotada (figurationibus) coincide a dos cinco testemunhos da tradição direta, sugerindo ser a genuína.

Citação 16. Si laboraveris manifeste contemni ab hominibus, faciet te Deus gloriari; ${ }^{22}$ studeas despici, et repleberis honore divino. (Pecham, cap. 12, 1s. 119-121; Migne, cap. 13, col. 828).

a. Variantes da tradição indireta: manifeste] manifesti $L_{2}$.

b. Variantes da tradição direta [LMi (15r22-23/26-27), LA (319r9-14), LAs 3 (36v711), $L P m$ (19v10-15) e $L F$ (11r21-24)]: hominibus] omnibus $L A L A s_{3} L F$; faciet te Deus] te Deus faciet $L A$; gloriari] glorificari $L M i$.

c. Comentários: No único lugar-crítico da tradição indireta, a variante adotada (manifeste) coincide com a dos cinco testemunhos da tradição direta, sugerindo ser a genuína.

Citação 17. Sicut, inquit, pater gerit curam filii sui, ita Deus gerit curam corporis, quod pro Christo affligitur, et semper est iuxta illud. (Pecham, cap. 12, 1s. 131-133; Migne, cap. 14, col. 831)

a. Variantes da tradição indireta: inquit] om. $B L$; Christo] ipso $L_{2}$; est] om. $L$.

b. Variantes da tradição direta [LMi (17v25-27), LA (321v2-3), $L A s_{3}$ (38v8-9), LPm (23r14-17) e $L F$ (12v25-26)]: inquit] om. $L M i L A L A s_{3} L P m L F$; gerit curam] curam gerit $L M i L A L A s_{3}$; ita] ita et $L M i$; gerit curam²] curam gerit $L M i L A L F$; Christo] ipso $L M i L A L A s_{3} L P m L F$; et semper est] om. LF.

c. Comentários: No primeiro lugar-crítico da tradição indireta, a variante adotada (inquit) diverge em relação a dos cinco testemunhos da tradição direta,

${ }^{22} \mathrm{Na}$ tradição direta, há, entre a parte anterior a este ponto e a seguinte, dois períodos, que aparecem em $L A$ como "Quod, si habes humilitatem in corde tuo, ostendet tibi Deus gloriam Suam in corde tuo. Esto contemptus in magnitudine tua et non magnus in parvitate tua." 
sugerindo ser a genuína a outra (a omissão de inquit), presente, a propósito, em dois testemunhos da tradição indireta $(B$ e $L)$. No segundo lugar-crítico da tradição indireta, a variante adotada (Christo) diverge em relação a dos cinco testemunhos da tradição direta, sugerindo ser a genuína a outra (ipso), presente, a propósito, em um testemunho da tradição indireta $\left(L_{2}\right)$ : a origem dessa variante na tradição direta deve estar na leitura equivocada da abreviatura ipo (como xpo), presente, p. ex., em LMi. No terceiro lugar-crítico da tradição indireta, a variante adotada (est) coincide com a dos cinco testemunhos da tradição direta, sugerindo ser a genuína.

Citação 18. Quanto plus fatigatur et affligitur corpus, tanto magis tempore quo circumdat hominem acies daemonum cor eius a confidentia defensatur. (Pecham, cap. 12, 1s. 133-135; Migne, cap. 18, col. 843).

a. Variantes da tradição indireta: [nenhuma].

b. Variantes da tradição direta [LMi (27v13-15), LA (331r5-7), LAs 3 (47v11-13), LPm (36v24-27) e LF (19v28-30)]: affligitur] acteritur LF; circumdat] circundant $L A s_{3} L P m$; hominem] homines $L M i L A L A s_{3} L P m$, eum $L F$; eius] ipsius LMi LA LAs ${ }_{3}$, hominis LF.

c. Comentários: A ausência de variantes na tradição indireta impede inferências. É digno de nota o fato de LPm possuir uma variante (eius) divergente em relação à tradição direta mas coincidente com a tradição indireta.

Citação 19. In ventre repleto secretorum Dei scientia non exsistit etc. (Pecham, cap. 12, 1. 136; Migne, cap. 5, col. 816).

a. Variantes da tradição indireta: etc.] om. $B L$.

b. Variantes da tradição direta [LMi (4r25), LA (309r8-9), LAs 3 (27v11-12), LPm (5v27-6r1) e $L F$ (3r17)]: secretorum Dei] secreto de $L P m$; etc.] om. LMi LA LAs LPm LF.

c. Comentários: No único lugar-crítico da tradição indireta, a variante adotada (etc.) diverge em relação a dos cinco testemunhos da tradição direta, sugerindo ser a genuína a outra (a omissão de etc.), presente, a propósito, em dois testemunhos da tradição indireta $(B$ e $L)$.

Citação 20. Lugens est, qui vitam in fame et siti ducit omnibus diebus vitae suae propter spem futurorum bonorum; divitiae religiosi sunt consolatio, quae fit ex luctu, et laetitia quae fit ex fide. (Pecham, cap. 12, 1s. 139-141; Migne, cap. 15, col. 831)

a. Variantes da tradição indireta: [nenhuma]. 
b. Variantes da tradição direta [LMi (18r1-4), LA (321v6-8), LAs (38v10-12), LPm (23r21-26) e $L F$ (12v27-28)]: vitam in fame et siti] in fame ac siti vitam $L M i L A$ $L A s_{3}$, in fame et siti vitam $L P m$, in fame et siti $L F$; religiosi] monachi $L M i$; sunt consolatio] consolatio sunt $L F$.

c. Comentários: A ausência de variantes na tradição indireta impede inferências.

Citação 21. "Quicunque vult post me venire, prius abneget semetipsum", ${ }^{23}$ ut sicut ille qui paratus est ascendere in crucem, assumit in mente sua mortis intentionem ac sic egreditur velut homo cogitans se non habere partem vitae iterum in hac vita; ita et qui perficere vult praedicta, nam crux est ad omnem tribulationem parata voluntas. (Pecham, cap. 12, 1s. 157-161; Migne, cap. 18, col. 839).

a. Variantes da tradição indireta: mente sua] mentem $L$; se non habere] om. $L_{2}$; ita] om. $L$; voluntas] voluntas etc. $L_{2}$.

b. Variantes da tradição direta [LMi (24v10-16), LA (328r10-16), LAs 3 (44v9-13), LPm (32v15-22) e LF (16v20-24)]: prius] om. LF; ascendere in crucem] ascendere in cruce $L A L A s_{3}$, crucem ascendere $L P m$, ascendere crucem $L F$; mente sua] corde suo $L P m$; ac sic] hac si $L A$; cogitans se non habere partem vitae] cogitans se non habere vite partem $L M i L A s_{3} L P m$, cogitans se vite non habere partem $L A$, non cogitans habere partem $L F$; et] facere debet $L F$.

c. Comentários: No primeiro lugar-crítico da tradição indireta, a variante adotada (mente sua) coincide com a dos cinco testemunhos da tradição direta, sugerindo ser a genuína. No segundo lugar-crítico da tradição indireta, a variante adotada (se non habere) coincide com a de três testemunhos da tradição direta $\left(L M i, L A s_{3}\right.$ e $\left.L P m\right)$, sugerindo ser a genuína. No terceiro e quarto lugares-críticos da tradição indireta, as variantes adotadas (respectivamente, ita e voluntas) coincidem com a dos cinco testemunhos da tradição direta, sugerindo serem as genuínas.

Citação 22. Qui ieiunium negligit, apud cetera propugnacula laxus erit et infirmus. (Pecham, cap. 12, 1s. 226-227; Migne, cap. 18, col. 843)

a. Variantes da tradição indireta: erit] est $B L_{2}$.

b. Variantes da tradição direta [LMi (27v20-21), LA (331r14-13), LAs 3 (47v16-17), LPm (37r7-8) e LF (19r4-5)]: ieiunium negligit] negligit jejunium LF; erit] est LMi LA LPm LF, om. LAs.

c. Comentários: No único lugar-crítico da tradição indireta, a variante adotada (erit) diverge em relação a de quatro testemunhos da tradição direta ( $L M i$, $L A, L P m$ e $L F)$, sugerindo ser a genuína a outra (est), presente, a propósito, em dois testemunhos da tradição indireta $\left(B\right.$ e $\left.L_{2}\right)$.

${ }^{23}$ Citação de Mateus, 16:24. 
Citação 23. Quando diabolus videt hanc armaturam super aliquem hominem, statim terretur adversarius et in continenti venit sibi in recordationem superationis suae quam a Salvatore passus est in deserto et virtus eius comburitur in armatura quae data est a principe nostro. (Pecham, cap. 12, 1s. 227-231; Migne, cap. 18, col. 842-843)

a. Variantes da tradição indireta: hominem] om. L; adversarius] om. L; in armatura] et invernatur $L$.

b. Variantes da tradição direta [LMi (27v5-10), LA (330v29-331r3), $L A s_{3}(47 \mathrm{v} 6-10)$, $L P m$ (36v14-21) e LF (19v23-26)]: Quando diabolus] diabolus quando LMi LA $L A s_{3} L P m L F$; super] apud $L M i L A$; adversarius] adversarius et tirannus $L M i$ $L A s_{3} L P m$, om. $L A L F$; in continenti] om. LF; venit] om. LA; sibi] om. LMi LA $L A s_{3} L P m L F$; in] ad $L M i L A L A s_{3} L F$; recordationem] recordatione $L A$; Salvatore] Salvatore nostro $L P m$; quae data est] que data nobis est $L M i$, que data est nobis $L A s_{3}$, nobis data $L F$.

c. Comentários: No primeiro lugar-crítico da tradição indireta, a variante adotada (hominem) coincide com a dos cinco testemunhos da tradição direta, sugerindo ser a genuína. No segundo lugar-crítico da tradição indireta, a variante adotada (adversarius) coincide parcialmente com a de três testemunhos da tradição direta $\left(L M i, L A s_{3}\right.$ e $L P m$ e $\left.L F\right)$, pois aparece nestes seguida de et tirannus, sugerindo ser parte de uma variante genuína: note-se, a propósito, que a variante não-adotada, presente em um testemunho da tradição indireta $(L)$, coincide com a de dois dos testemunhos da tradição direta ( $L A$ e $L F)$. A ausência de et tirannus em parte da tradição direta ( $L A$ e $L F$ ) pode ser um caso de salto-bordão, pois está entre duas palabras iguais, a conjunção et (... adversarius et tirannus et...). No terceiro lugar-crítico da tradição indireta, a variante adotada (in armatura) coincide com a dos cinco testemunhos da tradição direta, sugerindo ser a genuína.

Citação 24. ... ideo qui ieiunii armatura vestitur, omni tempore est accensus et zelotes; Elias, cum zelavit pro lege Dei, in hac armatura vicit. (Pecham, cap. 12, 1s. 231-233; Migne, cap. 18, col. 843)

a. Variantes da tradição indireta: ideo] $o m$. $B L_{2}$; Elias] hec Elias $L$.

b. Variantes da tradição direta [LMi (27v15-17), LA (331r7-9), LAs 3 (47v13-14), LPm (36v27-37r3) e LF (18v30-19r2)]: ideo] om. LMi LA LAs ${ }_{3} L P m$ LF; et] om. $L F$, et enim $L P m$; zelavit] zelaret $L A s_{3}$; vicit] vixit $L M i L A L P m$.

c. Comentários: No primeiro lugar-crítico da tradição indireta, a variante adotada (ideo) diverge em relação a dos cinco testemunhos da tradição direta, sugerindo ser a genuína a outra (a omissão de ideo), presente, a propósito, em dois testemunhos da tradição indireta $\left(B\right.$ e $\left.L_{2}\right)$. No segundo lugar-crítico da 
tradição indireta, a variante adotada (Elias) coincide com a dos cinco testemunhos da tradição direta, sugerindo ser a genuína.

Citação 25. Hic est ordo sobrius et Deo amabilis, indumentis vilibus contentum esse ad necessitatem corporis et sic cibis ad sustentationem uti, non gastrimargiae causa, et participare parum de omnibus, et non hoc exprobare et hoc eligere, ut impleat ex ipsis ventrem; major est enim omni virtute districtio vinum praeter debilitatem aut infirmitatem non sumere. (Pecham, cap. 12, 1s. 309-314; Migne, cap. 53, col. 883).

a. Variantes da tradição indireta: Hic] om. $L$; sic] sicut $L$; participare] parcitate $L$; exprobare] reprobare $B L_{2}$; et $\left.{ }^{2}\right] \mathrm{om}$. $L$; hoc] illud $L_{2}$; enim] om. $L$; districtio] discretio $L_{2}$; praeter] propter $L$.

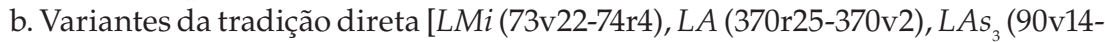
91r1), LPm (100r16-26) e LF (47r8-14)]: indumentis] Non respicere oculis hinc inde, sed semper ante se, non otiosa verba preferre sed tantum neccessaria $L M i$, Non respicere oculis hinc inde, sed semper ante se, non otiosa verba loqui sed tantum neccessaria $L A L A s_{3} L P m$, Non respicere [...] novitiorum oculis hinc inde, sed semper ante se, non otiosa verba et juvenum loqui sed tantum neccessaria $L F$; contentum] contectum $L A$; sustentationem] sustentationem corporis $L M i L A L A s_{3} L F$; sic cibis] cibis $L P m$; uti] Et sic uti $L A s_{3}$; gastrimargiae causa] castrimargie $L M i L A L A s_{3} L F$, castrimargie servire $L P m$; non hoc] etiam hec $L P m$; exprobare] reprobare $L M i L A L A s_{3} L P m L F$; hoc] hec $L P m$; impleat] in $L A s_{3}$; ventrem] ventrem suum $L M i L P m$; enim] tibi $L M i$; districtio] discretio $L M i L A L A s_{3} L P m L F$; debilitatem aut infirmitatem] infirmitatem aut debilitatem $L M i L A L_{3} L P m L F$.

c. Comentários: No primeiro, segundo e terceiro lugares-críticos da tradição indireta, as variantes adotadas (respectivamente, Hic, sic e participare) coincidem as dos cinco testemunhos da tradição direta, sugerindo serem as genuínas. No quarto lugar-crítico da tradição indireta, a variante adotada (exprobare) diverge em relação aos cinco testemunhos da tradição direta, sugerindo ser a genuína a outra (reprobare), presente, a propósito, em dois testemunhos da tradição indireta $\left(B\right.$ e $\left.L_{2}\right)$. No quinto, sexto e sétimo lugares-críticos da tradição indireta, as variantes adotadas (respectivamente, et, hoc e enim) coincidem as dos cinco testemunhos da tradição direta, sugerindo serem as genuínas. No oitavo lugar-crítico da tradição indireta, a variante adotada (districtio) diverge em relação aos cinco testemunhos da tradição direta, sugerindo ser a genuína a outra (discretio), presente, a propósito, em um testemunho da tradição indireta $\left(L_{2}\right)$. No nono lugar-crítico da tradição indireta, a variante adotada (praeter) coincide com a dos cinco testemunhos da tradição direta, sugerindo ser a genuína. 
Citação 26. ... habere vultum pallidum et rugosum, lacrimari nocte dieque etc. (Pecham, cap. 12, 1s. 343-344; Migne, cap. 24, col. 852).

a. Variantes da tradição indireta: lacrimari] jejunare $L_{2}$; etc.] om. $L$.

b. Variantes da tradição direta [LMi (73v22-74r4), LA (344r18-19), LAs 3 (60v8-9), LPm (57v24-26) e LF (28r26, com lacuna neste ponto)]: rugosum] rugosam faciem $L P m$; lacrimari] lacrimare $L M i L P m$; etc.] om. $L M i L A L A s_{3} L P m$.

c. Comentários: No primeiro lugar-crítico da tradição indireta, a variante adotada (lacrimari) coincide com a de apenas dois testemunhos da tradição direta ( $L A$ e $L A s_{3}$ ), mas, como a segunda variante da tradição direta (lacrimare) é lexicalmente compatível com a primeira variante e não tem afinidade com a variante não-adotada da tradição indireta (jejunare), parece seguro considerar a primeira (lacrimari) como a genuína. No segundo lugar-crítico da tradição indireta, a variante adotada (etc.) diverge em relação a dos cinco testemunhos da tradição direta, sugerindo ser a genuína a outra (a omissão de etc.), presente, a propósito, em um testemunho da tradição indireta $(L)$.

Citação 27. Quamlibet virtutem sine labore corporis factam reputa sicut abortivum exanime; oblatio iustorum lacrimae oculorum suorum et sacrificium eorum acceptabile gemitus eorum; in vigiliis clamabunt ad Dominum pondere corporis angustiati et in dolore preces ad eum emittent. Communicant angelis sanctis in passionibus et tribulationibus ob suam propinquitatem. (Pecham, cap. 12, 1s. 397402; Migne, cap. 17, col. 835).

a. Variantes da tradição indireta: reputa] repente $L$.

b. Variantes da tradição direta [LMi (21v8-15), LA (325r4-13), $L A s_{3}$ (41v14-20), LPm (28r26-28v9) e LF (15v6-14)]: factam] acquisitam LF, om. LPm; abortivum exanime] abortum exanimem $L M i$; oculorum suorum] suorum oculorum $L F$; eorum ${ }^{1}$ om. $L F$, ipsorum $L P m$; vigiliis] vigiliis. Oratio humilis tanquam ab ore ad aures Dei. O Domine Deus meus, illumina tenebras meas, in tempore tranquillitatis tue clama in operibus bonis humilitatis $L F$, vigiliis. (na margem: Oratio humilis tanquam ab ore ad aures Dei. Domine Deus meus, in tempore tranquillitatis tue clama in operibus humilitatis bonis) $L A s_{3}$; pondere] justi pondere $L M i L A L A s_{3} L P m L F$; preces ad eum] preces ad eum $L M i$, preces ad Dominum $L F$, ad eum preces $L A s_{3}$; emittent] mittent $L F$; Communicant] et in clamore vocis sue sancti ordines ad auxilium eorum accedent ut confortent eos in spe et consolentur. Communicant enim $L A$, et in clamore vocis sue sancti ordines ad auxilium eorum accedent ut confortent eos et in spe consolentur. Communicant enim $L M i L_{1} s_{3} L P m$ LF; angelis] angeli $L M i L A L_{3}$ $L P m L F$; passionibus] passionibus suis $L F$; tribulationibus] tribulationibus suis $L A L F$; ob suam propinquitatem] propter propinquitatem suam $L F$, ob propinquitatem suam $L P m$. 
c. Comentários: No único lugar-crítico da tradição indireta, a variante adotada (reputa) coincide com a dos cinco testemunhos da tradição direta, sugerindo ser a genuína.

Há 72 lugares-críticos relativos às citações da obra de Isaac de Nínive no Tractatus Pauperis de John Pecham, ou seja, na sua tradição indireta. Em 48 $(67 \%)$ deles, os editores de Pecham escolheram a variante que efetivamente era compatível com a maioria dos testemunhos da tradição direta aqui analisados ( $L M i, L A, L A s_{3}, L P m$ e $\left.L F\right)$, o que sugere que sua escolha terá recaído sobre as variantes efetivamente genuínas. Em 24 (33\%) casos, no entanto, a escolha da variante da tradição indireta não é compatível com a tradição direta; são eles:

(a) cit. 1 (cap. 11): prolongemus] prorogemus $B V L_{2}$;

(b) cit. 2 (cap. 6): etiam (no cap. 6, não há et depois)] et $O B$;

(c) cit. 4 (cap. 1): Qui] Quibus $B L L_{2}$;

(d) cit 4 (cap. 1): hujusmodi] om. $B L_{2}$;

(e) cit. 6 (cap. 1): Humilitatis est preferre accusationes falsas] om. O;

(f) cit. 7 (cap. 5): deferat] destruat $B$;

(g) cit. 8 (cap. 5): fortitudo] sollicitudo $L_{2}$, formido $L$;

(h) cit. 8 (cap. 6): Quod] om. O;

(i) cit. 10 (cap. 6): aliquibus] aliquo $B L$;

(j) cit. 12 (cap. 11): cum viderit] videns $L$, cum videt $B V$;

(k) cit. 12 (cap. 11): obviet] obviat $B V L L_{2}$;

(l) cit. 13 (cap. 11): Sic] om. $L_{2}$;

(m) cit. 13 (cap. 11): scilicet] videlicet $V L_{2}$;

(n) cit. 14 (cap. 11): sanctitate] sanitate $L$;

(o) cit. 14 (cap. 1): etc.] om. BVL;

(p) cit. 15 (cap. 12): tuas] om. $B L_{2}$;

(q) cit. 17 (cap. 12): inquit] om. BL;

(r) cit. 17 (cap. 12): Christo] ipso $L_{2}$;

(s) cit. 19 (cap. 12): etc.] om. BL;

(t) cit. 22 (cap. 12): erit] est $B L_{2}$;

(u) cit. 24 (cap. 12): ideo] om. $B L_{2^{\prime}}$;

(v) cit. 25 (cap. 12): exprobare] reprobare $B L_{2}$;

(x) cit. 25 (cap. 12): districtio] discretio $L_{2}$;

(y) cit. 26 (cap. 12): etc.] om. L.

A escolha das variantes da tradição indireta incompatíveis com o que sugere a tradição direta concentra-se nos caps. 1, 5, 6, 11 e 12: os três primeiros 
editados por Van den Wyngaert (1925), com 9 escolhas inadequadas, e os dois últimos por Delorme (1944), com 15 escolhas inadequadas. A questão fundamental é por que, nesses casos, a escolha não foi a mais adequada?

No caso das 9 escolhas inadequadas de Van den Wyngaert (1925), verifica-se uma relação complexa entre os critérios da variante do testemunho-base e da mais frequente. ${ }^{24} \mathrm{Em} 4$ casos (d, f, g, i), o editor ficou com a variante que estava no testemunho-base e era a mais frequente, ou seja, com a que seria esperada levando em conta o material que lhe estava disponível. Em 2 casos (c, o), ficou com a variante do testemunho-base, mesmo não sendo a mais frequente; e em $3(b, e, h)$, ficou com a variante mais frequente, mesmo não estando no testemunho-base.

No caso das 15 escolhas inadequadas de Delorme (1944), a complexa relação entre os critérios de escolha de variantes também se manifesta. Diferentemente de Van den Wyngaert (1925), Delorme (1944) adota 2 testemunhos-base $\left(L\right.$ e $\left.L_{2}\right)$, sem indicar a qual deles daria maior peso. Em 9 casos (a, $\mathrm{l}, \mathrm{m}, \mathrm{p}, \mathrm{r}, \mathrm{t}, \mathrm{u}, \mathrm{v}, \mathrm{x})$, o editor escolheu a variante mais frequente e presente em $L_{2}$; em 4 casos (n, q, s, y), a mais frequente e presente em $L$; em 1 caso (j), a presente em $L_{2}$ e não poderia usar o critério da frequência por haver empate entre duas variantes; e em 1 caso $(\mathrm{k})$, curiosamente elege a variante que não está nos testemunhos-base (a de $\left.V_{2}\right)$ e nem é a mais frequente.

Esses 24 casos de escolha inadequada da variante poderiam de forma geral ter sido sanados se os editores de Pecham tivessem consultado testemunhos da tradição direta de Isaac de Nínive. Entretanto, a simples consulta a algum testemunho da tradição direta não seria suficiente, pois algumas das variantes inadequadas escolhidas aparecem efetivamente na tradição direta, tal é o caso de (a), (d), (g), (j) e (m): é preciso comparar também diferentes testemunhoa da tradição direta, e não apenas consultar um deles.

A coincidência entre variantes não-genuínas na tradição indireta e direta da obra de Isaac de Nínive é interessante. Alguns casos poderiam ser erros poligenéticos: tal seria o caso de troca de letras (como em (a)), de omissões (como em (d)), de adaptações morfossintáticas (como em (j)) e de automatismos de cópia (como em (m)). Entretanto, em um caso específico (g) é possível que a questão seja mais complexa, pois adotou-se na tradição indireta uma variante não-genuína que existe na tradição direta e não parece poder ser fruto de erro poligenético: a variante não-genuína fortitudo existe tanto em $O B V$ da tradição indireta como em $L F$ da tradição direta.

\footnotetext{
${ }^{24}$ Para uma lista de critérios tradicionalmente empregados em edições críticas, conferir Cambraia (2005: 149-59).
} 
Esse emparelhamento poderia estar indicando de qual testemunho (ou família) da tradição direta Pecham teria retirado as citações de Isaac; entretanto, um recorrido pela análise de cada uma das 27 citações realizada mais acima permite ver que é justamente $L F$ o testemunho cujas variantes mais freqüentemente se afastam do texto da tradição indireta, razão pela qual parece pouco provável que este testemunho específico tenha sido de fato o modelo para Pecham. Se o emparelhamento nesse caso não seria atribuível a erro poligenético nem à condição de modelo principal para Pecham, uma hipótese provável é a existência de contaminação da tradição indireta pela tradição direta e, nesse caso, parece haver condições históricas que justificam a proposta, pois tanto os testemunhos $L$ e $L_{2}$ da tradição indireta quanto o testemunho $L F$ da tradição direta pertencem a um mesmo fundo (Biblioteca Laurenciana), sendo provenientes de uma mesma instituição (Biblioteca Sanctae Crucis). Trata-se, naturalmente, de uma contaminação infeliz, já que o testemunho LF é um dos que mais apresenta erros na tradição latina (Autor1, 2008).

\section{CONSIDERAÇÕES FINAIS}

O objetivo deste estudo foi refletir sobre as relações entre tradição direta e indireta na difusão da tradução latina da obra de Isaac de Nínive. Foi possível perceber que uma análise comparativa entre essas duas tradições contribui para um melhor conhecimento da difusão da obra de Isaac de Nínive bem como para a reconstituição da forma genuína tanto da obra de Isaac como do texto de Pecham:

(a) O fato de o texto de Pecham apresentar a obra de Isaac basicamente sob o título De perfectione contemplationis sugere que essa tenha sido uma das primeiras formas com que circulou na tradução latina (como aparece em LPm da tradição direta), pois, como já se mencionou, o título ganhou várias formas ao longo de difusão da tradição direta da obra de Isaac, presentes já nos testemunhos mais antigos.

(b) O fato de o texto de Pecham fazer menção a certas divisões da obra de Isaac sugere que os testemunhos que apresentam divisão compatível com a presente em Pecham estariam mais próximos da divisão genuína (dos testemunhos da tradição direta analisados, seriam $L M i$ e $L A s_{3}$ ).

(c) $\mathrm{O}$ confronto entre as variantes da tradição indireta e da tradição direta da obra de Isaac permitiu verificar que nem todas as escolhas de variantes realizadas pelos editores de Pecham foram necessariamente as mais 
adequadas, pois algumas delas são incompatíveis com o que sugere a tradição direta.

(d) Esse mesmo confronto permitiu identificar identidade entre certas variantes não genuínas tanto na tradição indireta quanto na direta, sugerindo assim ter havido contaminação da tradição indireta pela tradição direta.

Em síntese, este estudo demonstrou que, no processo de reconstituição da forma genuína de textos do passado na forma de edições críticas, é importante confrontar tradição direta e indireta, pois esse confronto permite decisões mais seguras e embasadas na escolha de variantes, bem como reconstrução da história da difusão dos textos

\section{REFERÊNCIAS}

Brock, S. 1999-2000. "From Qatar to Tokyo, by way of Mar Saba: the translations of Isaac of Beth Qatraye (Isaac the Syrian)." Aram 11/12: 475-84.

Cambraia, C.N. 2005. Introdução à crítica textual. São Paulo: Martins Fontes.

Cambraia, C.N. 2008. "Elementos para a reconstrução da tradição latina do Livro de Isaac." Comunicação apresentada no II Congreso Internacional de Estudios Clásicos en México, na Universidade Nacional Autónoma de México, na cidade do México, no período de 8 a 12 de setembro de 2008.

Cambraia, C.N.; Laranjeira, M.B. 2010. "Tipologia dos erros na tradição latina do Livro de Isaac." Caligrama (Belo Horizonte) 15: 7-48.

Chialà, S. 2002. Dall'ascesi eremitica alla misericordia infinita: ricerche su Isaaco di Ninive e la sua fortuna. Firenze: Leo S. Olschki.

Delorme, F. 1925. Fr. Richardi de Mediavilla Quaestio disputata de privilegio Martini papae IV. Quaracchi: Typrografia S. Bonaventurae.

Delorme, F. 1932. "Trois chapitres de Jean Pecham pour la défense des Ordres mendiant." Studi Francescani (Firenze) 29 (3 $3^{\text {a }}$ ser.): 47-62, 164-93.

Delorme, F. 1944. "Quatre chapitres inédits de Jean de Pecham, o.f.m., sur la perfection religieuse et autres états de perfection." Collectanea Franciscana (Roma-Assisi) 14: 84-120.

Doucet, V. 1946. "Angelus Clarinus, Ad Alvarum Pelagium, Apologia pro vita sua." Archivum Franciscanum Historicum 39: 63-200.

Fabricius, J. A. 1790-1809. Bibliotheca graeca. Hamburg: Carolvm Ernestvm Bohn.

Gribomont, J. 1960. "La scala paradisi: Jean de Raithou et Ange Clareno." Studia Monastica (Barcelona) 2: 345-58.

Grynaeus, J. J. 1569. Monvmenta s. patrom orthodoxographa. Basel. (T. V: 1626-1677.)

Kingsford, C. L.; Little, A. G.; Tocco, F., eds. 1910. Fratris Johannis Pecham quondam Archiepiscopi Cantuariensis Tractatus Tres de Paupertate. Aberdeen: Typis Academicis. (British Society of Franciscan Studies, II) 
Migne, J.-P. 1865. Patrologiae cursus completus: series graeca, vol. 86. Paris: Ed. do Autor (1815-75).

Munitz, J. 1974. "A greek Anima Christi prayer." Eastern Churches Review 6: 170-80.

Potestà, G. L. 1990. Angelo Clareno: dai poveri eremiti ai fraticelli. Rome: Istituto Storico Italiano per il Medio Evo.

Van den Wyngaert, A., ed. 1925. Tractatus pauperis a fratre Johanne de Pecham conscriptus. Paris: Éd. de la France Franciscaine.

*

Abstract. The reconstruction of the path followed by the work of Isaac of Nineveh in its diffusion in the Latin presents many challenges, given the large geographical and temporal range. In this paper, we examine the quotes of Isaac of Nineveh in John Pecham's Tractatus Pauperis in order to get better evidence about the history of their diffusion in Latin and to discuss the relationship between direct and indirect tradition in the process of preparing critical editions.

Keywords. Isaac of Nineveh, Latin Language, Textual Criticism, Critical Edition. 